Nejc SLUKAN*

\title{
POLITIKA IRONIJE NA SPLETNIH DRUŽBENIH OMREŽJIH: ORIS MEDIJSKO-TROLOVSKEGA DISPOZITIVA**
}

\begin{abstract}
Povzetek. Namen članka je postaviti teoretsko podlago za analizo ironičnih komunikacijskih praks na spletnih družbenih omrežjih. Posebej se bomo posvetili praksam trolanja. V članku ne definiramo ironije le kot retorične figure, temveč tudi kot govorno dejanje, ki rekonfigurira razmerje med elementi komunikacijske situacije. Najprej bomo kritično ovrednotili sodobne različice teorij tehnoloških zmožnosti, nato pa skozi prikaz komunikacijskih pogojev na nekaterih spletnih družbenih omrežjih pokazali, kako je mogoče določene njihove zmožnosti opisati kot del dispozitiva, ki ga delovno imenujemo medijsko-trolovski dispozitiv in ki posameznike spodbuja k trolovskim oblikam izražanja. Naša zaključna ugotovitev je, da zmožnosti spletnih družbenih omrežij spodbujajo trolovske oblike izražanja.

Ključni pojmi: ironija, trolanje, dispozitiv, zmožnosti, spletna družbena omrežja
\end{abstract}

\section{Uvod}

Sodobno mediatizirano politično govorico, posebej tisto, ki jo najdemo v spletni retoriki desnih populizmov (Nagle, 2017; Weatherby, 2019), močno zaznamujejo ironične oblike izražanja, ki jih danes navadno imenujemo trolanje (Coleman, 2014; Phillips, 2015; Phillips in Milner, 2017; Weatherby, 2019). Izraz trol (ang: troll) na prvi pogled označuje fantastična humanoidna bitja iz skandinavske mitologije, vendar izvira - v svojem spletnem kontekstu - iz izraza za muharjenje (ang. trolling), pri katerem vabo na trnku vlečemo po vodi - v upanju, da bo riba zagrabila vabo (Phillips, 2015). Iz tega opisa že lahko sklepamo na določeno značilnost trolovskega vedenja - posameznik/ca nastavlja past, ki vzpostavlja distinkcijo med ribiči in ribami - troli in trolanimi. Začetne rabe izraza troll ali trolling v internetnem

* Nejc Slukan, asistent, Fakulteta za družbene vede, Univerza v Ljubljani, Slovenija.

** Izvirni znanstveni članek.

Članek je nastal v okviru usposabljanja mladih raziskovalcev, ki ga financira ARRS pri programu P6-0400.

DOI: $10.51936 /$ tip.58.2.391-408 
kontekstu segajo v čas Useneta ${ }^{1}$ (Phillips, 2015: 16), na katerem so se oblikovale prve spletne subkulture (Pfaffenberger, 2003: 27). Že zelo zgodaj se je na Usenetu $\mathrm{v}$ devetdesetih razvila dinamika interakcije med starejšimi, bolj izkušenimi in mlajšimi, bolj nevednimi, uporabniki in uporabnicami. Trolanje je v svoji začetni internetni obliki nastalo kot praksa smešenja in prepoznavanja novih uporabnikov. Izkušenejši/a uporabnik/ca bi npr. kot odgovor na vprašanje novinca/ke, ki bi bilo percipirano kot neumno ali naivno, $v$ vsakem primeru pa kot znamenje neposvečenosti v spletno skupnost, objavil večini starejših uporabnikov znano preteklo objavo, ki je bila že večkrat predmet smešenja (praksa, iz katere se pravzaprav rodi internetni $\mathrm{mem}^{2}$ ). Reakcija novinca/ke bi nato pokazala ali ta izkazuje zadostno vednost ali omiko (npr. zmožnost premetenega odziva), da je lahko štet/a kot član pogovorne skupnosti. Ta zgodnji primer trolanja kaže tudi na eno izmed njegovih ključnih značilnosti, tj. delovanje agregativne funkcije ironije (Hutcheon, 1994: 86-110), ki za svoje delovanje potrebuje diskurzivno skupnost, katere meje so simbolno reproducirane ob vsaki ponovni rabi trolovske komunikacije (Gal et al., 2017). Čeprav je trolanje praksa, ki jo navadno povezujemo z nastankom sodobnega uporabniškega spleta in še posebej s posebno subkulturo njegovih uporabnikov zbranih okoli anonimnih spletnih forumov, kot je npr. 4chan (Phillips, 2015: 72; Erasmus, 2019), pa je v svojih formalnih značilnostih prisotna $v$ javnem govoru že od nekdaj (Coleman, 2014; Kravanja, 2017).

Trolanje bomo definirali kot retorološko figuro (Avanessian, 2015: 15-23) in govorno dejanje (Austin, 1990), ki učinkuje z vzpostavitvijo posebne konfiguracije razmerij med govorcem $/ \mathrm{ko}^{3}$ (ali več govorci/kami), sogovorcem/ko (ali več sogovorci/kami), diferenciranim občinstvom in govorno situacijo samo. Situacija, v kateri govorec/ka trola sogovorca/ko, je situacija, v kateri govorec/ka taktično pretirava v izražanju svojih stališč do te mere, da pri sogovorcu/ki vzpodbudi odziv, ki v svoji afektivni investiciji presega afektivno investicijo prvotne/ga govorke/ca (Kravanja, 2017). Ta afektivno pretiran odziv je možen iz dveh razlogov: 1) zaradi tega, ker je

1 "Usenet ("users network" - [uporabniška mreža op. p.]) je bil globalni internetni pogovorni sistem na osnovi teksta, ki je nastal v zgodnjih osemdesetih in je prenehal delovati v poznih dvatisočih. Vnjem so uporabniki/ce objavljali in brali sporočila drug drugega znotraj kategorij, ki so se nanašale na različne teme in so bile poznane kot newsgroups [skupine za novice op. p.] ter hierarhično razdeljene v podteme, $k i$ so bile označene z relevantnimi predponami (npr. rec.sport.basketball.college)."(Warf, 2018: 890)

2 Internetni mem je po definiciji, ki jo postavi Shifman (2014), skupina digitalnih predmetov (ki se pojavljajo v različnih oblikah - tekst, video, avdio, multimodalne vsebine), ki si delijo vsebino in/ali formo in/ali držo, so ustvarjeni na podlagi vednosti ustvarjalcev o tej skupini predmetov in množično cirkulirajo po internetu. Navadno so sestavljeni kot kolaž iz različnih kulturnih referenc.

3 Tu uporabljamo izraza govorec/ka in sogovorec/ka, ki implicirata poseben medij komunikacije, govor, kot sinonima, ki veljata tudi za komunikacijske situacije, kjer medij posredovanja komunikacije ni govor, temveč tudi npr. tekst ali vizualno sporočanje. 
sogovorec/ka nezmožen/a prepoznati taktično naravo govorčevega/kinega pretiravanja ali 2) ker kljub prepoznavanju taktike uporabe trolovskega govora sogovorec/ka le-to smatra za posebej neprimerno trenutni govorni situaciji. S tem se sogovorec/ka pred določenim delom občinstva, ki razume intenco govorčevega pretiravanja in/ali se strinja s širšo intenco govorca nasploh in/ali pristaja na njegovo/njeno komunikacijsko normo oz. definicijo situacije, osmeši, ravno tako pa to govorno dejanje v veliko primerih razdeli občinstvo na dva dela. Prvi del, ki razume pretiravanje kot izvajanje retorološke figure in/ali jo smatra za primerno situaciji, in drugi del, ki ali vzame pretiravanje zares in se s tem ravno tako hkratno osmeši pred govorcem/ko in preostalim občinstvom ali pa jemlje pretiravanje kot neprimerno in si s tem spet prisluži posmeh govorca/ke in prvega dela občinstva, zaradi lastnega odklanjanja ludične (Hutcheon, 1994: 46-47) norme govorice, ki jo je govorec ravnokar poskusil vsiliti v trenutno definicijo situacije (Goffman, 2015). Zaradi svoje agregativne funkcije, ki zmeraj temelji ne le na povezovanju neke diskurzivne skupnosti, temveč tudi na začrtovanju njenih mej, je trolanje inherentno politični komunikacijski akt, ki deli posameznike/ce na tiste, ki pripadajo neki skupnosti, in tiste, ki ji ne.

$\mathrm{Na}$ tem mestu je potrebno pojasniti, kaj smo imeli v mislih s tem, ko smo trolanje kot obliko ironije opredelili kot retorološko in ne zgolj kot retorično figuro. Standardna retorična definicija ironije razume ironijo kot preprosto neskladje med manifestnim pomenom nekega komunikacijskega akta in njegovo pravo vsebino, pri čemer sta ta dva elementa $v$ medsebojnem protislovju - pravi pomen je nasproten manifestnemu pomenu tega, kar komuniciramo. Obe sistematični študiji ironije, na katere se pri svojem delu posebej sklicujemo (Hutcheon, 1994; Avanessian, 2015), poudarjata, da je ravno tovrstna tradicija zgolj retoričnega razumevanja ironije odgovorna za poenostavljeno razumevanje le-te. Če bi namreč ironija merila zgolj na posredovanje pomena, ki je nasproten manifestni vsebini sporočenega, bi pravzaprav težko pojasnili, kaj točno je njena komunikativna funkcija, mimo tega, da služi kot stilistično sredstvo. Obe študiji poudarjata, da funkcija ironičnega komunikacijskega akta ni predvsem komunikacija svojega nasprotja, temveč komunikacija nečesa tretjega - navadno nekega razmerja. To razmerje pa je lahko npr. odnos govorca/ke do sogovorca/ke, do občinstva, do neke specifične tematike, do definicije situacije, $v$ katero je trenutni govor vpet, itd. V običajni ironični govorni situaciji se te odnosi celo prepletajo $\mathrm{v}$ različnih kombinacijah. S tem pa postane ironično govorno dejanje nekaj, kar presega retoriko kot umetnost prepričevanja ter vključuje tudi vzpostavljanje, utrjevanje ali rušenje trenutne definicije situacije in odnosov med akterji in elementi v njej. Podobno kot performativ (Austin, 1990), govorno dejanje, ki proizvaja realnost, na katero se sklicuje, ima tudi ironija (in s tem tudi trolanje) socialno-ontološko funkcijo. Zaradi te dvojne 
(retorične in socialno-ontološke) vloge Avanessian ironijo (in posebej njene moderne oblike) opredeli kot retorološko.

Kljub temu je mogoče reči, kot ugotavlja več študij, da je trolanje posebej pogosto v spletnem okolju (Coleman, 2014; Phillips, 2015; Nagle, 2017; Phillips in Milner, 2017). V članku bomo pokazali, da razmere, v katerih poteka sodobna spletna komunikacija, posebej pa komunikacija na spletnih družbenih omrežjih, spodbujajo trolovske komunikacijske prakse. V njem bomo tako pritrdilno odgovorili na vprašanje, ali je mogoče pogostost trolovske komunikacije na spletu analizirati kot produkt niza lastnosti vmesnikov spletnih družbenih omrežij. Ta odgovor bomo podali v obliki konstrukcije koncepta medijsko-trolovskega dispozitiva, ki lahko služi kot podlaga za nadaljnje empirične raziskave vpliva pogojev komuniciranja na spletnih družbenih omrežjih na komunikacijo na njih.

Pogoje, ki jih bomo postavili kot ključne pri razumevanju tega, moramo razumeti na specifičen način, tj. kot del logike vmesnika, ki jo razvije Galloway (2012), torej kot serijo »tehničnih dispozitivov, ki težijo k vzpodbujanju skupine praks, ki producirajo fleksibilno, modularno in neskončno spremenljivo obliko oblasti« (Topinka, 2019). Vmesnik, ki posreduje med uporabnikom/co in vsebino na spletu, tj. prisotnost in razporejenost funk-

394 cij na konkretnih spletnih družbenih omrežij ter serija splošnih značilnosti računalniško posredovane komunikacije (Walther, 1996; 2007), je pravzaprav skupek zmožnosti (ang: affordances) (Bucher in Helmond, 2018). Ta skupek zmožnosti bomo razumeli prek kritične apropriacije Agambenove interpretacije poznega Foucaultovega koncepta dispozitiva, da bi prišli do tega, kar bomo delovno poimenovali medijsko-trolovski dispozitiv.

\section{Teorija zmožnosti in spletna družbena omrežja}

Za začetnika teorije zmožnosti velja ameriški psiholog Gibson (1977). Njegova teorija se je v svoji izvorni obliki nanašala na razumevanje potencialov nekega predmeta v odnosu do akterjev, ki z njim nekaj počnejo. Nek predmet, denimo roža na travniku, ima drugačno vlogo za različne akterje, ki z njo stopijo v stik. Za mimoidočega polža predstavlja hrano, za hrošča streho med nalivom, za človeka pa npr. zgolj estetski objekt. Zmožnosti te rože so niz odnosov, ki se vzpostavijo med posameznimi akterji in predmetom ter omogočajo različne interakcije. Ključno predelavo Gibsonove zastavitve najdemo v Normanovi (1988) prilagoditvi teorije zmožnosti $\mathrm{v}$ teorijo oblikovanja. Zmožnosti nekega predmeta so, po Normanovi oceni, praktično neskončne, zato je potrebno, če hočemo imeti aplikativno teorijo oblikovanja, njihovo razumevanje zožiti na zmožnosti, ki jih posamezni predmet relativno jasno sporoča akterjem, ki bodo z njim upravljali. Pravilna raba predmeta mora biti torej nakazana že v njegovi obliki ali z 
jasno razumljivimi znaki. Norman spremeni težišče razumevanja zmožnosti iz relacijskih značilnosti interakcije med akterjem in predmetom na sporočilne značilnosti predmeta samega, medtem ko Gaver (1991) njegovo zastavitev tipizira in razdeli zmožnosti na zaznavne, skrite in lažne. Normanov konceptualni premik omogoči Hutchbyju (2001) izpeljavo argumenta, da koncept zmožnosti pomeni razrešitev teoretskega nasprotja med tehnološkimi deterministi in socialnimi konstruktivisti na področju študij uporabe tehnologij. Zmožnosti tehnologij razume kot lastnosti, ki zamejujejo polje možnih uporab, a vendar puščajo dovolj odprtega prostora za to, da najrazličnejši družbeni vplivi rezultirajo v različnih praksah uporabe. ${ }^{4}$ Problem argumentov, ki sledijo Normanovi prilagoditvi koncepta zmožnosti, pa je, da pri svojem vztrajanju na zmožnostih kot lastnostih oblikovanega predmeta zanemarijo konkretno situirano naravo vsakokratne rabe slednjih. Nagy in Neff (2015) tako ugotavljata, da

... imajo [uporabniki/ce, op. p] lahko določena pričakovanja do svojih komunikacijskih tehnologij, podatkov in medijev, ki v praksi oblikujejo načine, na katere $k$ njim pristopijo in za katere mislijo, da so predlagani. Ta pričakovanja niso nujno vključena $v$ oblikovanje uporabniških orodij, vendar vseeno tvorijo zaznavo dejanj, ki so uporabnikom na voljo. (Nagy in Neff, 2015: 5)

Po Gibsonu je razprava o zmožnostih odrinila na stran ravno prednost njegovega relacijskega koncepta. Nagy in Neff (2015) zato ponudita koncept zamišljenih zmožnosti kot rešitev tega teoretskega problema. Zamišljene zmožnosti so zmožnosti, ki jih npr. uporabnik/ca neke spletne platforme na njej razume kot take. Čeprav so ustvarjalci vmesnika neke platforme zanj predvideli določen spekter uporab, so konkretne zmožnosti uporabe, ki jih uporabniki dojemajo kot take, zmeraj produkt kompleksnega razmerja med njihovimi dispozicijami na eni strani in konkretno materialnostjo vmesnika na drugi.

Shaw (2017) njuno teorijo zmožnosti kot pristop za razumevanje novih medijev nadgradi z adaptacijo Hallovega (2012) modela ukodiranja in razkodiranja. Interpretacijo praktičnih zmožnosti, ki jih dovoljuje posamezna

4 Z uporabo koncepta zmožnosti se Hutchby (2001) postavi na vmesno pozicijo med konstruktivizmom in realizmom, ki je še najbolj sorodna teoretikom ATN (actor-network theory), npr. Latourju, Lawu in Callonu. Za opis odnosa ATN do drugih paradigem s področja študij znanosti in tehnologije glej npr. Luthar (2007). Hutchby se od teoretikov ATN razlikuje predvsem po tem, da jasneje loči vlogo človeških in nečloveških akterjev ter strožje analitično razlikuje človeške smotre in materialne značilnosti objektov, pri čemer se izogne prestrogemu dualizmu družba/tehnologija, prek poudarka na zmožnosti, kot koncept, ki opisuje odnos vzajemnega učinkovanja in konstrukcije med človeškimi intencami in materialnostjo objek tov. 
tehnologija, razume prek Hallove delitve na dominantno-hegemonska, pogajalska in opozicijska branja medijskih tekstov ter te tri moduse branja razume kot moduse "potencialnih aktivnosti z novo-medijskimi teksti, objekti in formami« (Shaw, 2017: 597). Pri poskusu aktualizacije teorije interpretacije medijskih tekstov na področje novomedijsko posredovanih komunikativnih praks pa moramo biti previdni. V takšnem početju namreč zmeraj tiči nevarnost, da interpretiramo značilnosti posameznega vmesnika kot tekst ${ }^{5}$ (Hutchby, 2001). S tem bi zavrgli eno izmed glavnih prednosti koncepta zmožnosti, apliciranega na vmesnike, torej poskus razumevanja načinov, na katere oblike tehnološkega posredovanja uokvirjajo delovanja uporabnikov. Sama forma nekega vmesnika omogoča niz zmožnosti, ki sledijo neposredno iz njegove tehnične narave; ta niz zmožnosti pomeni polje omejitev, ki onemogočajo, da bi bili vmesniki zgolj tabula rasa, na katero lahko projiciramo katerokoli zamišljeno zmožnost. Tehnična narava vmesnikov omogoča zamišljanje šele v drugem koraku.

$\mathrm{Na}$ tem mestu predlagamo dodatno razširitev Shawovega modela. Na eni strani imamo tako različne stopnje odmika od dominantno-hegemonskih rab $v$ odnosu do vmesnika, na drugi strani pa različne stopnje odmika znotraj vmesnika. Ta razdelitev se nam zdi pomembna, ker omogoča vzpostavitev dvojne kritične pozicije za razumevanje komunikacije prek novih medijev. S tem mislimo, da mora kakršnakoli kritična analiza novih medijev vzeti v obzir dva vidika. Na eni strani tehnološki in ekonomski aspekt infrastrukture novih medijev, ki stoji v ozadju konkretne manifestne oblike vmesnika, pri čemer se naš odnos do teh aspektov kaže v obliki rab $v$ odnosu do vmesnika, na drugi strani pa analizo vsebine in dinamike komunikacijskih praks znotraj vmesnika, ki se kažejo prek raznolikih načinov uporabe manifestnega dela vmesnikov spletnih družbenih omrežij.

Prvo kritično pozicijo bomo bolje razumeli, če se navežemo na delo Srniceka (2016), ki analizira različne spletne platforme (med katere sodijo tudi spletna družbena omrežja) kot sestavne dele platformnega kapitalizma in poudarja dejstvo, da večina profitov in družbene moči le-teh izhaja iz popolnega beleženja delovanja uporabnic/kov na njih. Beleženi podatki imajo ekonomsko vlogo surovine, na podlagi katere je mogoče opravljati podatkovne analize, ${ }^{6}$ ki koristijo poslovnim ali političnim interesom akterjev, ki uporabljajo spletne platforme za (predvsem) marketinške namene, posebej pa platformi sami kot ponudniku takih storitev. $Z$ vidika proizvajanja podatkovne sledi je vsak komunikacijski akt na spletnem družbenem omrežju nekaj, kar veča maso podatkov in s tem surovine, ki je platformi

5 Glej npr. Woolgar in Grint (1997).

6 Pri temu Srnicek eksplicitno kritizira tezo Terranove (2000), ki izhaja iz operaističnega koncepta družbene tovarne, po kateri naj bi kakršnokoli udejstvovanje na spletnih družbenih omrežjih predstav ljalo direktno obliko dela. 
na voljo. ${ }^{7}$ To pomeni, da je kakršnakoli raba $v$ odnosu do vmesnika spletnih družbenih omrežij, ki pretendira k opozicijski ali vsaj pogajalski poziciji, nujno vezana na uporabo metod, ki so v subverzivnem odnosu do mehanizmov, prek katerih dotične platforme vršijo svoje operacije ekstrakcije podatkov, s ciljem nadaljnjega ustvarjanja profita. Skratka, nujno ustreza definiciji tega, kar se v internetni kulturi imenuje exploit ${ }^{8}$ in zahteva določeno mero inženirskih znanj na področju informacijskih tehnologij in programiranja.

Namen tega članka pa je predvsem konceptualizacija druge kritične pozicije. Medtem ko je mogoče najti oblike trolanja $\mathrm{v}$ praksah, ki sodijo pod širšo domeno hekerskega delovanja na spletu in odnosa do vmesnikov, nas bo tukaj, z druge perspektive, zanimala predvsem trolovska ironija, ki jo najdemo v spletnih praksah, ki se odvijajo znotraj vmesnikov, torej tistih, ki so omogočene znotraj nekaterih najpogostejših komunikacijskih okvirjev sodobnih oblik računalniško posredovane komunikacije.

\section{Mediji in koncept dispozitiva}

V svoji interpretaciji Foucaultovega koncepta dispozitiva Agamben (2006) pokaže ključno vlogo, ki ga ta zaseda v Foucaultovem razmišljanju o oblikah vladnosti, hkrati pa poudari, da Foucault v svojih tekstih koncepta nikoli eksplicitno ne definira. Po Agambenu se definiciji najbolj približa v intervjuju iz leta 1977:

Kar poskušam definirati s tem imenom, je predvsem popolnoma heterogen skupek, ki prepleta diskurze, institucije, arhitektonske strukture, regulativne odločitve, zakone, administrativne ukrepe, znanstvene izreke, filozofske, moralne in filantropske propozicije, skratka, tako izrečeno kot neizrečeno, ki tvorijo elemente dispozitiva. Dispozitiv je mreža, ki se vzpostavi med temi elementi. (Foucault, Michel (1994): Dits et écrits, vol. III, 299-300; citirano iz: Agamben, 2006: 6-7)

Agamben iz tako široke definicije izpelje ontologijo, na kateri temeljijo poznejša Foucaultova dela in deli stvarnost na tri kategorije - substance ali živa bitja, dispozitive in subjekte, ki niso ontološka realnost zase, temveč so presečišče med prvima dvema, pri čemer je lahko vsako živo bitje subjektivirano s strani mnoštva dispozitivov, ki jih ta opredeli kot »... dobesedno katerokoli stvar, ki ima na nek način zmožnost ujeti, orientirati, določiti,

7 Couldry in Mejias (2019) uporabljata v tem kontekstu kar metaforo kolonizacije, pri čemer je tisto, kar je kolonizirano, naše družbeno življenje.

8 Exploit je izraz za izkoriščanje neke napake ali pomanjkljivosti v programiranem okolju, kjer posamezniki le-to izkoristijo, da bi prišli do rezultata, ki jim ponuja preprosto zabavo ali pa je celo usmerjen $k$ politično obarvani subverziji. Za več o temi glej Galloway in Thacker (2007). 
prestreči, modelirati, kontrolirati in zagotoviti geste, vedenja, mnenja in diskurze živečih bitij« (Agamben, 2006: 21-22). Agambenovo razumevanje Foucaultovega koncepta dispozitiva je širši konceptualni okvir, znotraj katerega razumemo prej omenjeni govor o zmožnostih. Zmožnosti novih medijev, ki jih bomo opisali, tvorijo torej nek dispozitiv.

Preden se lotimo razlage sestave tega, kar bomo poimenovali medijsko-trolovski dispozitiv, torej mreže, ki jo sestavljajo predvsem štirje ključni elementi, pa bomo predhodno odgovorili še na nekaj potencialnih pomislekov na takšno konceptualizacijo. Andreasen (2019) na primeru medijev opozarja, da koncepta zmožnosti in dispozitiva implicirata različni perspektivi. Zmožnost je tako predvsem to, kar medij uporabnikom/cam omogoča, medtem ko koncept dispozitiva implicira perspektivo, pri kateri medijski dispozitiv uporabnike medija določa v njihovem delovanju. Skratka, če prvi temelji na razumevanju odnosa med akterjem in medijem, kjer je njun odnos relativno simetričen (ni mogoče reči, da narava neke naprave ali vmesnika bolj vpliva na njeno rabo kot uporabnik/ca sam/a), pa perspektiva koncepta dispozitiva opozarja na asimetrijo razmerij moči, ki so vgrajene v delovanje vsake dispozitivne mreže. A vendar se že Andreasen v zaključku istega teksta naveže na Deleuzeov (2015) pripis h konceptu družbe nadzora 398 in zaključi, da predstavljajo uporabniški vmesniki spletnih družbenih omrežij območje, kjer ni mogoče razlikovati med nudenjem zmožnosti in določanjem uporabniškega delovanja s strani dispozitivov. Vmesniki spletni družbenih omrežij ustvarjajo množice prosumerjev - hkratnih potrošnikov in producentov vsebin, nad katerimi se oblast vrši ravno prek njihovega aktivnega angažmaja z zmožnostmi vmesnikov.

Drugi resnejši pomislek se tiče razmerja med tem, kar tukaj koncipiramo kot medijsko-trolovski dispozitiv, in drugimi dispozitivi, s katerimi je mogoče opisati sodobno realnost novih medijev, predvsem spletnih družbenih omrežij. Ta naloga je vse prej kot enostavna in - vsaj v smislu popolne razmejitve - nemogoča. Kot pravi Agamben, ima koncept dispozitiva v Foucaultovem delu predvsem strateško vlogo (Agamben, 2006: 5), v smislu tega, da mu ponuja možnost konceptualnega povezovanja različnih elementov, ki sodelujejo v produkciji konkretnih oblik oblasti. V tem smislu je ravno sodobnost kot obdobje množenja dispozitivov hkrati tudi obdobje prekrivanja le-teh, posebej na ravni njihovih posameznih elementov, ki lahko igrajo različne vloge $\mathrm{v}$ različnih dispozitivnih mrežah.

$\mathrm{Na}$ tem mestu bi opozorili predvsem na analizo Terranove (2015), ki poudarja prenos mehanizmov neoliberalne sekuritizacije, o katerih govori Foucault v svojih delih o biopolitiki, na spletna družbena omrežja. Ti mehanizmi temeljijo predvsem na seriji dispozitivov varnosti kot "prostorskih tehnologij oblasti, ki se tičejo predvsem upravljanja s cirkulacijo« (prav tam: 114) in težijo predvsem k njeni »ekspanziji in stabilizaciji« (prav tam). 
Čeprav se Foucaultova prvotna analiza osredini predvsem na načine upravljanja populacij, ki so osredotočeni predvsem na telesa, pa je mogoče, kot to stori Terranova in kot poudarja Han (2017), ko predlaga uvedbo termina psihopolitika, tovrstno razumevanje upravljanja s cirkulacijo razširiti tudi na sfero komunikacije ter psiho-socialnega življenja prebivalstva. Psihopolitični dispozitivi, o katerih posredno govori Terranova, stojijo v ozadju spletnih družbenih omrežij kot obliki kontrolirane družbenosti, ki se, podobno kot sfera politike, podrejajo imperativom trga, ki služi v neoliberalni epohi kot model preoblikovanja vseh družbenih institucij. Ta razmislek, ki smo ga v prejšnjem razdelku uvrstili predvsem $\mathrm{v}$ obliko kritike rab $v$ odnosu do vmesnika (katerega primarni namen je, kot rečeno prej z drugimi besedami, omogočiti čim večjo količino kontrolirane cirkulacije informacij), seveda pomembno vpliva tudi na dinamiko samih procesov komunikacije, ki se vršijo znotraj vmesnika. Polje konceptualizacije, ki se ga lotevamo v tem članku, pa je nekoliko ožje in bolj specifično ter služi dopolnitvi razumevanja prepleta že opisanih dispozitivov s še neopisanim.

Zadnji pomislek, ki ga bomo tukaj na kratko omenili, sta vloga in stanje subjekta in subjektivacijskih procesov v kontekstu mnogih dispozitivov, ki določajo posameznike/ce. Kot izhodišče bomo vzeli Agambenovo tezo, da sodobno, skorajda nepregledno množenje dispozitivov, ki določajo posameznike/ce, ne rezultira v procesih subjektivacije, temveč v splošnem porastu procesov desubjektivacije. ${ }^{9}$ Te procesi naj bi ustvarjali predvsem posameznike/ce, ki so nezmožni povezovanja v kolektivne politične subjekte, in s tem onemogočali grajenje družbene solidarnosti. Čeprav je več kritikov opozorilo na pretirano pavšalnost Agambenove teze, ki npr. ponavlja presežene dualizme med tehničnim uokvirjenjem delovanja in avtentično eksistenco (Stiegler, 2010: 160-171) ter podcenjuje vlogo politično-ekonomskih kategorij pri razumevanju vpliva dispozitivov na našo (de)subjektivacijo (Fischbach, 2012: 48-54), pa je vendarle pri tematiki dispozitivov vprašanje subjekta in subjektivacije neobhodno. Stališče, ki ga zato tukaj zavzemamo in ki bo postalo nekoliko bolj jasno iz opisov v naslednjem razdelku, je, da se ni mogoče postaviti na načelno, kategorično stališče glede razmerja med subjektivacijo in desubjektivacijo $\mathrm{v}$ delovanju medijsko-trolovskega dispozitiva. Čeprav se zdi, da je efemerna narava spletne komunikacije nekaj, kar v splošnem podpira Agambenovo tezo, pa lahko že v drugem elementu spodaj opisanega dispozitiva najdemo potencial tako za bolj kot manj stabilne oblike subjektivacije. V primeru trolanja kot prakse začrtovanja mej lastne diskurzivne skupnosti je tako mogoče najti element, ki izkazuje izrazito pripadnost neki družbeni skupini ali npr. političnemu prepričanju. Glede na

9 Agambenov izraz je sicer nekoliko hiperboličen - desubjektivacija je zanj proces proizvajanja efemernih, zgolj začasnih subjektivitet, za razliko od bolj trajnih oblik subjekta. 
kompleksno naravo posameznikove/čine pripadnosti neki družbeni skupini, ki je v spletnem kontekstu dodatno zakomplicirana s strani efemerne narave komuniciranja na njem, pa je odgovor na vprašanje trdnosti in trajnosti posameznih subjektivacij na spletni družbenih omrežij mogoče najti zgolj na ravni konkretnih študij primerov.

\section{Trolovsko-medijski dispozitiv}

Splet in njegove platforme predstavljajo največji obstoječi arhiv predhodno objavljenih medijskih vsebin, vendar ima običajni način, prek katerega do njih dostopamo, drugačno strukturo kot dostopanje do njih prek drugih, starejših medijev. Če na kratko ponazorimo to misel: ogled posnetka, ki je predvajan na televiziji, določa precej drugačna situacija recepcije kot ogled posnetka, ki se nahaja na spletnem družbenem omrežju Youtube. Posnetek je na Youtube naložil določen uporabnik in ga opremil s komentarjem, pod katerim se nahajajo komentarji drugih uporabnikov. Do nas je prišel, potem ko ga je objavil nekdo, ki mu sledimo na spletnih družbenih omrežjih; objava je potencialno spet opremljena tako s komentarjem objavljajoče osebe kakor tudi ostalega občinstva s seznama prijateljev, ki mu je posnetek na voljo. Že postavitev televizijske vsebine na nek kanal, v nek časovni termin, format televizijske oddaje in druge okoliščine, v katere je neka oddaja umeščena, ${ }^{10}$ kontekstualizirajo sporočilno vrednost videnega posnetka na način, prek katerega mu podelijo dodaten nabor konotacij, ki jih ni mogoče odkriti na ravni njegove manifestne vsebine, temveč izhajajo iz specifičnega prepleta razmerja med kontekstom, sporočevalcem, prejemnikom, vsebino in modalnostjo sporočila. ${ }^{11}$

Za ironijo kot retorično sredstvo je $\mathrm{v}$ formalnem smislu ključno neskladje med posameznimi elementi komunikacijske situacije iz prejšnjega odstavka. Čeprav je tovrstno neskladje možno pravzaprav v vsaki komunikacijski situaciji in v vsakem tipu medija, se število njenih posamičnih elementov na spletnih družbenih omrežjih drastično poveča, s tem pa tudi njene materialne zmožnosti proizvodnje ironije in s tem trolovske komunikacije. Spletna družbena omrežja, kot sta npr. Facebook ali Twitter, ${ }^{12}$ imajo v svoj vmesnik vgrajeno možnost deljenja vsebin, ki so že bile deljene drugje na

10 Primer tega je npr. postavitev oddaje pred in po določeno interstiticijsko (ang: interstitial) vsebino (reklame, napovedi itd.), ki jo opisuje Ellis (2011). Umeščenost oddaje med te vsebine, po ugotovitvah avtorja, upliva na njeno recepcijo.

11 Glej npr. Fiske in Hartley (2003), posebej poglavja 3, 4, 5 in 7.

12 Ta dva primera izpostavljamo zgolj kot verjetno najbolj znana bralstvu - zelo podobne funkcije imajo tudi druga spletna družbena omrežja in aplikacije za instantno pošiljanje sporočil, od Wechata do Telegrama, kljub določenim posebnostim vsakega izmed njih (Instagram npr. ne dovoljuje enakega tipa deljenja vsebin). 
platformi, s preprostim klikom na gumbe share oz. retweet, medtem ko velik del spletnih strani zunaj teh platform ravno tako ponuja integracijo z njihovimi funkcijami. Ta oblika deljenja vsebin omogoča, da lahko s preprostim klikom spremenimo kontekst, $\mathrm{v}$ katerem je vsebina percipirana. To nam predstavlja prvo izmed ključnih zmožnosti komuniciranja na spletnih družbenih omrežjih in sodobnem uporabniškem spletu nasploh - (1) vseprisotnost orodij za resignifikacijo ${ }^{13}$ (Weatherby, 2019). Zmožnost resignifikacije, tj. spremembe pomena vsebine na uporabniškem spletu, je v striktnem smislu sestavljena - njen pogoj je serija drugih predhodnih možnosti, ki jih Boyd (2011) postavi kot temeljne značilnosti rokovanja z vsebino na uporabniškem spletu - persistenca vsebine, njena replikabilnost, njena skalabilnost ${ }^{14}$ in možnost, da iščemo po različnih vsebinah. Da bi razumeli pomembnost resignifikacije obstoječih vsebin za npr. ironični humor, nam ni treba pogledati posebej na spletna družbena omrežja. Pomislimo preprosto na dnevnopolitično oddajo z ironičnim tonom, kot je Daily Show (Magill, 2007: 22). Oddaja, ki slovi po svoji humorni predstavitvi dnevnopolitičnih tem, je v veliki meri sestavljena zgolj iz segmentov, ki so vzeti iz poročanja drugih televizij in pri čemer je dovolj, da samo prestavimo izsek videovsebine in ga predstavimo novemu občinstvu, da dosežemo humorni učinek. To občinstvo v grobem tvori diskurzivno skupnost, tj. skupino ljudi, ki jih druži »kompleksna konfiguracija deljene vednosti, verjetij, vrednot in komunikativnih strategij« (Hutcheon, 1994: 87). Spletna družbena omrežja omogočajo sleherniku, da se poslužuje primerljivih manevrov resignifikacije kot avtorji dotičnih objav.

To nas pripelje do druge pomembne zmožnosti, zaradi katere se na sodobnem spletu trolovska komunikacija dogaja tako pogosto. Čeprav posamezne stopnje posredovanja posameznega sporočila, ki smo jih orisali, omogočajo vzpostavitev različnih oblik resignifikacije prvotne vsebine sporočila, pa bi razlike, ki se pojavijo, izzvenele v prazno, če ne bi imele na voljo različnih občinstev. Tisto, kar dela trolanje za posebej mikavno komunikacijsko modaliteto izražanja na spletu, je pravzaprav kompleksna interakcija med posameznimi diskurzivnimi skupnostmi. Čeprav je preplet različnih diskurzivnih skupnosti pojav, ki ga najdemo pravzaprav že od nekdaj, je treba upoštevati, da se pogostost takšnih interakcij veča v pozni modernosti ${ }^{15}$ in

13 Čeprav je resignifikacija, tj. prestavitev vsebine v drug kontekst, ki vpliva na njeno recepcijo, nekaj, kar lahko najdemo že v literarnih delih, o čemer priča mnogo literarnoteoretskih razprav okoli koncepta intertekstualnosti, ravno tako pa že na televiziji in radiu, pa predstavlja obča dostopnost enostavnih orodij za resignifikacijo novost, ki jo uvede šele uporabniški splet, posebej spletna družbena omrežja.

14 Skalabilnost pomeni zmožnost, da je lahko digitalna vsebina hitro in množično razširjena po spletu. Pri tem je pomembno imeti v mislih, kot pravi boyd, da »lastnost skalabilnost ne pomeni, da se širijo vsebine, ki jih posamezniki želijo razširiti ali tiste, za katere mislijo, da bi se morale razširiti, temveč da [spletni, op. p.] kolektiv odloča o tem, katera vsebina bo razširjena«(boyd, 2011: 48).

15 Pri razumevanju tega se naslanjamo predvsem na Harveyjevo (1989) analizo politično-ekonom 
da predstavlja uporabniški splet drastično povečanje možnosti takih srečanj. V svojem zgodnjem delu je boyd (2002) pod vplivom Meyrowitzeve (1985) študije o vplivu sodobnih medijev (predvsem televizije) na socialno dinamiko zmeraj večjega manka zamejitve med območji pravil, ki definirajo specifične družbene situacije, postavila tezo o kolapsu konteksta, ki ga prinašajo novi mediji. Zaradi tega, ker se na isti spletni platformi lahko srečajo najrazličnejše diskurzivne skupnosti, je posameznik na njej postavljen v situacijo, ko mora komunicirati na višji ravni taktičnosti, saj ima zmeraj opravka s kompleksno konfiguriranim občinstvom.

Čeprav predstavlja uporabniški splet območje vsaj deloma zamejenih grozdov (ang: clusters) uporabnikov, ki odražajo razlike med posameznimi družbenimi skupinami in so ravno tako osnovani na kulturnih distinkcijah razreda, spola, jezika in drugih pripadnosti, ki konstituirajo vsakršno diskurzivno skupnost, pa je vendarle mogoče reči, da trenutna struktura uporabniškega spleta omogoča bistveno lažje prehajanje med mesti, kjer se te skupnosti nahajajo. Veliko verjetneje je, da se bo naključni šaljivec, ki si o desnih populistih ne misli nič dobrega, znašel na njihovem profilu na Twitterju kot na kongresu njihove stranke. Sodobni splet tako omogoča (2) lažjo agregacijo specifičnih diskurzivnih skupnosti in bolj preprosto prehajanje med 402 njihovimi mesti srečevanja. To enostavno prehajanje pa - kot protiutež kolapsu konteksta - poveča potrebo po praksah ustvarjanja distinkcij in simbolnega začrtovanja mej ( $\mathrm{Gal}, 2018)$, ki konstituirajo diskurzivne skupnosti in temeljijo predvsem na ustvarjanju razlike med njihovo notranjostjo in zunanjostjo. Pomemben del teh praks postane tako tudi trolanje. $S$ tem ko nevedni/a uporabnik/ca ne prepozna trolanja, izkaže svojo nepripadnost skupnosti. To situacijo pa še posebej zaplete dejstvo, da je na spletu pogosto težko prepoznati komunikacijsko intenco posameznikov/ic.

Nemožnost ugotavljanja intence je ena izmed ključnih značilnosti situacij izražanja na spletu, ki poganja trolovske prakse. Te situacije so dovolj pogoste, da so že pred petnajstimi leti privedle do formulacije t. i. Poejevega zakona (Poe's law). Med debato o kreacionizmu na spletnem forumu christianforums.com, je leta 2005 uporabnik Nathanael Poe namreč ugotovil, da je »brez mežikajočega emotikona ali drugega očitnega izraza humorne namere ...... popolnoma nemogoče parodirati kreacionista, ne da bi to dejanje nekdo interpretiral kot iskreno" (Poe's Law). To nas privede do tretje zmožnosti, ki spodbuja spletno trolovsko komunikacijo in katere zametke najdemo že v zgodnji internetni kulturi anonimnosti in psevdonimnosti: ${ }^{16}$

\footnotetext{
ske dinamike pozne modernosti, katere rezultat je to, kar sam konceptualno opredeli kot časouno-prostorsko kompresija, in na analize Rose $(2013,2015)$, po kateri je temeljna poteza modernosti družbeno pospeševanje, ki se kaže na področjih tehničnega razvoja, sprememb družbenih institucij in zmeraj bolj frenetičnega živetega vsakdana.

${ }^{16}$ Psevdonimnost je situacija, kjer se posameznik/ca predstavlja s psevdonimom.
} 
(3) splošne pogostosti nepoznavanja drug drugega na spletu oz. zmožnosti ne biti prepoznan. Čeprav se na spletnih družbenih omrežjih, npr. na Facebooku ali Twitterju, posamezniki povečini predstavljajo s svojim imenom in priimkom, pa je situacij, $v$ katerih lahko pride do napačnega pripisovanja komunikacijske intence, pravzaprav ogromno. Vsaka večja, uporabnikom obče dostopna Facebook-skupina ali npr. vsaka nit komentarjev na profilu posameznega podjetja, teme ali znane osebnosti, pritegne navadno najrazličnejše uporabnike/ce, ki se med sabo povečini ne poznajo. Posebej $\mathrm{v}$ primerih, kjer gre za strani in skupine, ki so namenjene širši, mednarodni skupini uporabnic/kov, najdemo tako posameznike/ce, katerih intenco izrekanja lahko ugibamo zgolj na podlagi skopih informacij. Že zgodnje študije (Donath, 1995; Pfaffenberger, 2003) vedenja uporabnikov na Usenetu, na katerem je mogoče uporabnike identificirati prek elektronskega naslova, kažejo na najrazličnejše strategije manipulacij pri izkazovanju lastne identitete in namer.

Ravno tako kot je naše prepoznavanje intence osebe, ki nam nekaj sporoča, zaradi zgoraj naštetih faktorjev nekaj, kar je na uporabniškem spletu pogosto oteženo, sproža ta situacija določene učinke na strani tistega, ki nekaj sporoča. Pogosto so tako spletni/e uporabniki/ce, ki se postavijo v situacijo anonimnosti, psevdonimnosti ali pa jim preprosto ni mar glede potencialnih negativnih sankcij oz. le-teh sploh ni (Golf-Papež in Veer, 2017), posebej motivirani za to, da v svojem komuniciranju možnost lastne neprepoznavnosti tudi izkoristijo. Zabrisana sled za pravo identiteto posameznika/ce tako omogoča, da se posamezniki/ce poslužujejo najrazličnejših manipulacij, ki izkoriščajo nevednost njihovega občinstva, kakor tudi to, da izpovejo lastne intimne tegobe in dvome, ki bi jih sicer skrivali. Ta pojav, ki je v psihologiji znan kot dezinhibicijski učinek interneta (Suler, 2004; Joinson, 2007) in ga povzročajo različni dejavniki (anonimnosti, večje enakosti med posamezniki, asinhronosti komunikacije, vpliva disociativne imaginacije), ki doprinesejo $\mathrm{k}$ temu, da se posameznik na spletu vede na načine, na katere se sicer ne bi, je eden izmed ključnih pogojev obče razširjenosti trolovske komunikacije na internetu. Dezinhibicijski učinek interneta tvori posebej učinkovito kombinacijo skupaj z različnimi načini, na katere spletne platforme vplivajo na naše afektivne odzive. Gilroy-Ware (2017: 64-139) tako ugotavlja, da vse več psiholoških raziskav kaže na to, da ima obsedenost $z$ uporabo spletnih družbenih omrežij presenetljivo podoben značaj kot zasvojenost z igrami na srečo, pri kateri postanemo odvisni od anticipacije zadovoljstva. Po objavi, ki jo naredimo na spletnem družbenem omrežju, nastopi trenutek čakanja na morebitne odzive, ki v obliki komentarjev, všečkov, čustvenih simbolov in/ali nadaljnjega deljenja objavi podelijo določeno mero pozitivnega ali negativnega pripoznanja, ki ga skladno z našo začetno intenco - doživljamo na pozitiven ali negativen 
način. V tem smislu je vsaka objava hazarderska poteza, saj lahko zgolj poučeno ugibamo glede odzivov, na katere bo naletela. Čeprav so, kakor ugotavlja Gilroy-Ware, vmesniki spletnih družbenih omrežij oblikovani tako, da na posamezni platformi dosegajo čim večjo aktivnost pri uporabnikih, pa je "hazarderski« značaj objavljanja na spletu širša značilnost, ki presega zgolj spletna družbena omrežja. Kombinacija, ki doleti mnoge uporabnike spleta, je tako na eni strani dezinhibiranost, ki izvira iz anonimnosti ali iz disociativnega značaja računalniško posredovane komunikacije, na drugi strani pa želja po pozitivnem pripoznanju določenega števila uporabnikov, ki v grobem pripadajo podobni diskurzivni skupnosti. To nas pripelje do zadnjega izmed faktorjev, ki stojijo v ozadju trolanja kot posebej pogostega in mikavnega modusa komunikacije na internetu, tj. tega, da računalniško posredovana komunikacija deluje dezinhibicijsko, medtem ko ustroj spletnih družbenih omrežij in spletnih skupnosti - prek mehanizmov pripoznanja, ki so del samega vmesnika - spodbuja prakse, ki sprožajo močne afektivne odzive. Skratka, (4) splet ponuja zmožnosti pridobivanja pripoznanja, zadovoljstva in pozitivnih sankcij za trolanje.

\section{Sklep}

V članku smo prikazali, kako sta tako teorijo zmožnosti kot Foucaultov koncept dispozitiva, kakor ga interpretira Agamben (2006), primerni orodji za analizo pogojev sodobne komunikacije, v katerih se vršijo sodobne prakse ironičnega izražanja na spletu, $s$ posebnim ozirom na prakse trolanja kot primer retoroloških (Avanessian, 2015: 15-23) govornih dejanj, ki rekonfigurirajo razmerja med posameznimi elementi komunikacijske situacije in s tem producirajo družbeno realnost (Hutcheon, 1994: 9-37; Avanessian, 2015: 5-6).

Pri prikazu zmožnosti vmesnikov nekaterih izmed najpogosteje uporabljenih spletnih družbenih omrežij smo se osredotočili na tiste izmed njih, ki vzpostavljajo razmere za spodbujanje trolovskih komunikacije, in jih razdelili na štiri kategorije. Te kategorije so 1) vseprisotnost orodij za resignifikacijo vsebin, 2) enostavnejša agregacija posameznih diskurzivnih skupnosti in njihovo pogostejše medsebojno srečevanje, 3) pogostost nepoznavanja sogovorca/ke na spletu in s tem nemožnost pripisovanja intenc njegovim/ njenim komunikacijskim aktom in 4) sistem spodbud na spletnih družbenih omrežij, ki temelji na funkcijah všečkanja, deljenja, komentiranja in drugih ter omogoča posameznikom/cam pridobitev pripoznanja in s tem pozitivno valorizacijo znotraj neke diskurzivne skupnosti, katere meje, prek trolovskih praks, zmeraj vnovič začrta. Součinkovanje teh štirih zmožnosti spletnih družbenih omrežij smo delovno poimenovali medijsko-trolovski dispozitiv. Glavni prispevek članka je teoretska konstrukcija tega koncepta, 
prek katerega lahko analiziramo sodobne oblike spletne komunikacije kot določene s strani zmožnosti vmesnikov spletnih družbenih omrežij.

Delovanje medijsko-trolovskega dispozitiva v vsakem konkretnem primeru določa srečanje med posameznimi diskurzivnimi skupnostmi, katerih meje so okrepljene, začrtane in/ali rekonfigurirane s strani trolovske komunikacije. To vidimo kot posebej primerno izhodišče za nadaljnje empirične analize tega, kako lahko medijsko-trolovski dispozitiv vpliva na razmerja med diskurzivnimi skupnostmi na spletnih družbenih omrežjih v posamičnih situacijah. Takšne analize nam lahko pomagajo razumeti razmerje med efemernostjo in stabilnostjo diskurzivno določenih identitet, kot so npr. rasne, spolne, razredne, politične in druge pripadnosti, ter njihovega odnosa do lastne zunanjosti. Takšne raziskave se nam zdijo posebej pomembne v zgodovinskem trenutku, ki ga zaznamuje retorika desnih političnih populizmov, ki pogosto spretno izkoriščajo zmožnosti komunikacije na spletnih družbenih omrežij in se poslužujejo trolovske komunikacije. Članek je v tem smislu skromen prispevek k nadaljnjim študijam tovrstnih fenomenov.

\section{LITERATURA}

Agamben, Giorgio (2006): Che cos'è un dispositivo? Rim: nottetempo.

Andreasen, Torsten (2019): Destituting the Interface - Beyond Affordance and Determination. Dostopno prek http://mediatheoryjournal.org/torstenandreasen-destituting-the-interface/, 18. 1.2021.

Avanessian, Armen (2015): Irony and the Logic of Modernity. Berlin/Boston: de Gruyter.

Austin, John L. (1990): Kako napravimo kaj z besedami? Ljubljana: Studia Humanitatis.

Boyd, Danah (2002): Faceted Id/Entity: Managing Representation in a Digital World. Dostopno prek http://www.danah.org/papers/Thesis.FacetedIdentity. pdf, 15. 11. 2020.

Bucher, Taina in Anne Helmond (2018): The Affordances of Social Media Platforms. V: Burgess, Jean (ur.), Marwick, Alice (ur.) in Poell, Thomas (ur.). The SAGE Handbook of Social Media. Sage Publications, 233-253.

Coleman, Gabriella (2014): Hacker, Hoaxer, Whistleblower, Spy: The Many Faces of Anonymous. London/New York: Verso.

Couldry, Nick in Ulises A. Mejias (2019): The Cost of Connection: How Data Is Colonizing Human Life and Appropriating It for Capitalism. Stanford: Stanford University Press.

Donath, Judith (1998): Identity and Deception in the Virtual Community. V: Kollock, P. in Smith, M. (ur). Communities in Cyberspace. London: Routledge.

Deleuze, Gilles (2015): Pripis k družbam nadzora. V: Praznine : glasilo za arhitekturo, umetnost in bivanjsko kulturo 8: 82-83.

Ellis, John (2011): Interstitials: How the Bits in Between Define the Programmes. V: Grainge, Paul (ur.) Ephemeral Media: Transitory Screen Culture from Television to Youtube, 59-69. London: Bloomsbury. 
Erasmus, Dennis (2019): Containment Breach: 4chan's /pol/ and the Failed Logic of »Safe Spaces« for Far-Right Ideology. Dostopno prek http://www.boundary2. org/2019/07/dennis-erasmus-containment-breach-4chans-pol-and-the-failedlogic-of-safe-spaces-for-far-right-ideology/, 15. 11. 2020.

Fischbach, Franck (2012): Brez predmeta: Kapitalizem, subjektivnost, odtujitev. Ljubljana: Krtina.

Fiske, John in John Hartley (2003): Reading Television: Second Edition. London in New York: Routledge.

Gal, Noam (2018): Ironic humor on social media as participatory boundary work. V: New Media \& Society 21 (3) 729-749.

Gal, Noam, Limor Shifman in Zohar Kampf (2017): „It Gets Better«: Internet memes and the construction of collective identity. V: New Media \& Society 18 (8): 16981714 .

Galloway, Alexander, R. (2012): The Inteface Effect. Cambridge: Polity Press.

Galloway, Alexander in Eugene Thacker (2007): The Exploit: A Theory of Networks. Minneapolis: University of Minnesota Press.

Gaver, William W. (1991): Technology affordances. V: Proceedings of the SIGCHI conference on human factors in computing systems: reaching through technology, New Orleans, 27 April-2 May. 79-84. New York: ACM.

Gibson, James J. (1977): The theory of affordances. V: Shaw, Robert (ur) in Bransford, John D. (ur.), Perceiving, Acting and Knowing: Toward an Ecological Psychology, 67-82. Hillsdale: Erlbaum.

Gilroy-Ware, Mark (2017): Filling the Void: Emotions, Capitalism and Social Media. London: Repeater Books.

Golf-Papež, Maja in Ekart Veer (2017): Don't feed the trolling: rethinking how online trolling is being defined and combated. V: Journal of Marketing Management, DOI: 10.1080/0267257X.2017.1383298.

Goffman, Erving (2015): Predstavljanje sebe v vsakdanjem življenju. Ljubljana: Studia Humanitatis.

Harvey, David (1989): The Condition of Postmodernity: An Enquiry into the Origin of Cultural Change. London: Wiley/Blackwell.

Hutchby, Ian (2001): Technologies, texts and affordances. V: Sociology 35 (2): 441 456.

Hutcheon, Linda (1994): Irony's Edge: The Theory and Politics of Irony. London/ New York: Routledge.

Joinson, Adam N. (2007): Disinhibition and the internet. V: Gackenbach, Jayne (ur.). Psychology and the Internet: Intrapersonal, Interpersonal, and Transpersonal Implications, 76-92. San Diego/London: Academic Press/Elsevier.

Kravanja, Aljoša (2017): Zadržani srd: o retoričnem bistvu trolanja. Dostopno prek http://old.razpotja.si/aljosa-kravanja-zadrzani-srd-o-retoricnem-bistvu-trolanja/, 15. 11. 2020.

Luthar, Breda (2007): Mobilni telefon in pospešena kultura. V: Javnost 14. supl.: 5-18.

Meyrowitz, Joshua (1985): No Sense of Place: The Impact of Electronic Media on Social Behaviour. Oxford: Oxford University Press. 
Nagle, Angela (2017): Kill All Normies: Online Culture Wars from 4chan and Tumblr to Trump and the Alt-Right. London: Zero Books.

Nagy, Peter in Gina Neff (2015): Imagined Affordance: Reconstructing a Keyword for Communication. Dostopno prek http://sms.sagepub.com/content/1/2/ $2056305115603385,15.11 .2020$.

Norman, Donald (1988): The Psychology of Everyday Things. New York: Basic Books.

Pfaffenberger, Bryan (2003): A Standing Wave in the Web of Our Communications: Usenet and the Socio-Technical Construction of Cyberspace Values. V: Lueg, Cristopher (ur.) in Fisher, Danyel (ur.) From Usenet to CoWebs: Interacting with Social lnformation Spaces, 20-43. London: Springer.

Phillips, Whitney (2015): This Is Why We Can't Have Nice Things: Mapping the Relationship between Online Trolling and Mainstream Culture. Cambridge: MIT Press.

Phillips, Whitney in Ryan Milner (2017): The Ambivalent Internet: Mischief, Oddity and Antagonism Online. Cambridge/Malden: Polity Press.

Rosa, Hartmut (2013): Social Acceleration: A New Theory of Modernity. New York: Columbia University Press.

Rosa, Hartmut (2015): Accelerazione e alienazione: Per una teoria critica del tempo nella tarda modernita. Milano: Einaudi.

Shaw, Andrew (2017): Encoding and decoding affordances: Stuart Hall and interactive media technologies. V: Media, Culture \& Society 39 (4): 592-602.

Shifman, Limor (2014): Memes in Digital Culture. Cambridge: MIT Press.

Srnicek, Nick (2016): Platform Capitalism. Cambridge/Malden: Polity Press.

Suller, John (2004): The Online Disinhibition Effect. V: CyberPsychology \& Behavior 7 (3): 321-326.

Stiegler, Bernard (2010): Taking Care of Youth and the Generations. Stanford: Stanford University Press.

Terranova, Tiziana (2000): Free Labor: Producing Culture for the Digital Economy. Dostopno prek https://monoskop.org/images/6/6d/Terranova_Tiziana_2000_ Free_Labor_Producing_Culture_for_the_Digital_Economy.pdf, 15. 11. 2020.

Terranova, Tiziana (2015): Securing the Social: Foucault and Social Networks. V: Fuggle, Sophie et al. (ur.): Foucault and the History of Our Present. London: Palgrave Macmillan, 111-127.

Topinka, Robert (2019): Back to a Past that Was Futuristic: The Alt-right and the Uncanny form of racism. Dostopno prek http://www.boundary2.org/2019/10/ robert-topinka-back-to-a-past-that-was-futuristic-the-alt-right-and-the-uncannyform-of-racism/, 15. 11. 2020.

Warf, Barney (2018): Usenet. V: Warf, Barney(ur): The Sage Encyclopedia of the Internet. London: Sage Publications, 890-893.

Walther, Joseph B. (1996): Computer-mediated communication: Impersonal, interpersonal and hyperpersonal interaction. V: Communication Research 23: 342369.

Walther, Joseph B. (2007): Selective self-presentation in computer mediated communication: Hyperpersonal dimensions of technology, language, and cognition. V: Computers in Human Behavior 23: 2538-2557. 
Weatherby, Leif (2019): Irony and Redundancy: The Alt Right, Media Manipulation and German Idealism. Dostopno prek http://www.boundary2.org/2019/06/ leif-weatherby-irony-and-redundancy-the-alt-right-media-manipulation-and-german-idealism/, 15. 11. 2020.

Woolgar, Steven in Keith Grint (1997): The Machine at Work: Technology, Work and Organization. Cambridge/Malden: Polity Press.

\section{VIRI}

Poe's Law. (15. 11. 2020) Dostopno prek https://rationalwiki.org/wiki/Poe\%27s_ Law, 15. 11. 2020. 